\title{
IMMANUEL KANT Y LA IDEA DE IUS GENTIUM ${ }^{1}$
}

\author{
Wojciech BUCHNER \\ Profesor de Ciencia Política \\ Accademia Ignatianum de Cracovia (Polonia) \\ wbuchner@op.pl
}

El que tiene sentido histórico debe admitir que el ideario de la revolución francesa de hace dos siglos ha llegado a desarrollarse hoy en día hasta el paroxismo. El radicalismo social, el abolicionismo, la soberanía del poder legislativo malamente controlada, la susceptibilidad a la crítica incondicional de todo poder autoritario, todos esos hechos no son en cierto modo más que un eco del siglo XviII confiado en sus propias fuerzas. ;Sapere aude; , esta exclamación del gran Kant resonaba como una llamada a la revolución intelectual que iba a cambiar la faz del mundo según los principios nuevos. Sin embargo, la revolución en Francia había aplacado su exaltación. Kant se había despertado esta vez no de su duermevela metafísica, pero sí de su adoración temporal de las ideas de JeanJacques Rousseau.

Kant está hoy de moda. Eso es por la razón de que la idea de la unificación europea, como la de la Liga de Naciones de antes, descubre su patrono en la figura del filósofo y su filosofía del Derecho. No obstante, el proyecto kantiano del Derecho internacional parece hoy en día ser entendido muy vagamente, es decir, como el modelo más bien del liberalismo político que jurídico, mientras que el mismo Kant pensaba más bien de un estado jurídico —un status juridicus-.

Kant creía en la paz perpetua, pero sería un error destacar solamente el aspecto soñador de su pensamiento político y jurídico. El profesor prusiano estaba en este caso en una hibridación intelectual; por un lado, se dedicaba a las especulaciones sobre la respublica noumenon, pero, por el otro, como un filósofo del Derecho, observaba una disciplina cognoscitiva mayor. Además, viviendo bajo el poder absolutista de la monarquía prusiana admitía las duras leyes de la realidad.

${ }^{1}$ Conferencia impartida en el Instituto de Metodología e Historia de la Ciencia Jurídica de la UCM el pasado 21 de abril de 2015. 
La versión realista o metódicamente utopista son los dos tipos de pensamiento cuya coexistencia plasma la doble faz del pensamiento político kantiano. En la primera variante, al súbdito de Federico II lo encontramos como enemigo obstinado de la revolución cualquiera, recomendando la pasiva obediencia al poder soberano; como el partidario de la limitación de los derechos políticos, pero listo para aceptar sin duda el poder autoritario; como partidario de la pena de muerte en la época del abolicionismo que iba a surgir con Cesare Becaria, él se oponía al derecho real de gracia. No es difícil darse cuenta de que esta faz de Kant es más conforme al autoritarismo liberal de Tomás Hobbes que al democratismo radical de Rousseau. Vale la pena recordar que las ideas del liberalismo y de la democracia en el siglo XVIII no estaban todavía mezcladas y saturadas por los desiderata sociales y representaban idearios diferentes.

En los tiempos de la Ilustración, la monarquía enconada había dejado pasar el hecho de que la libertad del liberalismo no tiene que ser opuesta a las ciertas formas del poder autoritario. En el caso de Kant, la sumisión suya a la estilística francesa de la lengua política, entonces de moda, no es de ninguna manera un testimonio de la sumisión de su concepto del estado jurídico llamado Rechtsstaat a las tendencias radicales y antimonárquicas. Es por eso que parecen infundadas las tentativas sucesivas de los neokantistas para explotar la idea del Rechtsstaat en el marco del modelo del Walferstate. Basta apartarnos por un rato de los proyectos filosóficos de Kant y dirigirnos a sus conceptos jurídicos para descubrir bajo la máscara del radical dieciochesco (llamado por Heine «un Robespierre filosófico») los rasgos claros del pensamiento al mismo tiempo liberal y autoritario. Lo que le preocupa a él no es más que una pregunta principal: ¿de qué manera construir un Estado de derecho cuyo fin sería garantizar la esfera de la libertad igual a todos los individuos? Así pues, Kant se convierte al clásico del liberalismo y de la doctrina del Estado minimalista. Sin embargo, en sus especulaciones sucesivas, las cuales iban a explicar cómo debiera ser la institución del Estado de derecho, él se hizo esclavo de su lógica propia, habiendo hecho cuanto se pueda para que en el sistema del Rechtsstaat no apareciera ninguna fisura a través de la cual pudieran pasar unas competencias excepcionales del poder soberano. Eso es la pedantería, la que puede ser vista como la peculiaridad de la filosofía del Derecho kantiana. Y es justamente ella la que testimonia la creencia de Kant en que sería posible crear un orden jurídico hermético que no admitiera ninguna excepción a la regla. Aquí se trata sobre todo de la injerencia posible de la voluntad personal del soberano, por ejemplo, en la forma del derecho de 
gracia o de la decisión en los estados de emergencia. Podría parecer que la soberanía del Derecho excluye cualquier decisionismo. En realidad, como filósofo del Derecho, Kant es un enemigo de la excepción y de los precedentes. La idea del Derecho como un sistema que funciona automáticamente es extraña a la tradición anglosajona, pero para la tradición dieciochesca continental parece ser muy familiar. Es justamente en esta última en la que Kant se siente como en su casa.

La aversión a la excepción, es decir, a la infiltración de la decisión política en el orden hermético de la ley, iba a plasmar la faz segunda de Kant, la del idealista. Por ahora fijemos todavía la atención en la faz primera. Como realista, Kant no pasa de la respublica phenomenon y por eso tiene que aceptar la transcendencia del soberano. Él nos dice:

«La posición excepcional del soberano no resulta del contrato, pero del hecho, porque no es posible ningún contracto que nos obliga a nosotros a la obediencia pasiva: el poder soberano antecede al todo derecho»².

Eso implicaría que al susodicho contrato social no se lo puede imaginar hasta que el soberano tiene su posición inviolable, la que obliga a todos a la obediencia incondicional. Así pues, si el mandamiento de la obediencia pasiva no puede surgir del contrato social voluntario, tampoco el soberano puede aparecer en un Estado nacido del contrato ¿Quién, sin embargo, sustituirá al soberano en el Estado del Derecho? Es juntamente aquí donde nace la idea kantiana de la soberanía del Derecho, la que es, sin embargo, muy confusa, vacilando entre el concepto del contrato social de Rousseau y del pactum subjectionis de Hobbes. Kant confirma de la manera verdaderamente conservadora:

«Es muy agradable soñar de las formas del gobierno (especialmente en el aspecto jurídico), de las que responden a las exigencias de la razón, pero proponerlas sería arrogante y el instigarle al vulgo para que destruya las que ya existen debería ser castigable» ${ }^{3}$.

La otra forma del ingenio de Kant para poder domesticar el poder autoritario del soberano de la manera jurídica es su concepto de la lex per-

2 I. KanT, Handschriftlicher Nachlaß, Rechtsphilosophie, 8018, en Kants gesammelte Schriften, Band XIX, Berlin, Walter de Gruyter, 1934.

3 I. Kant, Der Streit der Fakultäten, Abschnitt II, 9, en Kants Werke, Band VII, Berlin, Akademie-Textausgabe In neun Bänden, 1968. 
missiva o Erlaubnisgesetz. No pudiendo reconciliarse con la arbitrariedad del poder soberano en las situaciones de emergencia, él se da por constreñido a introducir una regla gracias a la cual podría este poder usar la fuerza conforme con la ley. Aquí se trata de una forma de la ley excepcional, cuyos vestigios borrosos quedaron en las constituciones de los Estados de hoy como ecos lejanos de la dictadura constitucional antigua de los romanos. En este caso también sigue Kant la voz de la prudencia, dándose cuenta de que la libertad no se puede definir más que con relación a la coacción y a las limitaciones, porque la libertad política no es lo mismo que el libertinaje. No sin razón, pues, se cotejó de vez en cuando el Rechtsstaat con el Polizeistaat, lo que tenía que descontentarles a todos los admiradores y soñadores de la confederación de los estados libres de la violencia.

Dejando aparte la estilística dieciochesca, son los elementos conservadores en el pensamiento de Kant tan leíbles que no se puede no tenerlos en cuenta sin caer en la trampa del entusiasmo por su radicalismo supuesto. Además, se guarda el filósofo de una demagogia vulgar y, a la vez, se oculta detrás de los sueños cándidos y postulados racionalistas. Pero, por otro lado, hay que acordarse de que, entre las tres máximas romanas — boneste vivere, neminem laedere, sum cuique tribuere - que van a determinar el rumbo de la evolución hacia el Rechtsstaat, la última requiere un poder fuerte para hacerse eficaz. Igualmente, en el caso de la eficacia de las penas, lo que Kant recomienda es la severidad y observación del principio de la proporcionalidad entre la culpa y la pena — suum cuique retribuere, conforme con el derecho de la venganza justa (ius talionis) — . La defensa kantiana de la pena capital en la polémica con Cesare Beccaria forma un elemento transcendental de su faz realista y conservadora; aparte de eso, aquélla no es susceptible de la argumentación sociológica del abolicionismo, refiriéndose solamente a la necesidad de la restitución del orden y de la justicia como tal; por supuesto, aquí se trata de la justicia debida a la víctima.

La tensión entre la realidad triste y los postulados de la razón práctica la solucionaba Kant de la manera más audaz, a saber: él postulaba la unidad del mecanismo de la naturaleza y la libertad en el reino de los fines. La naturaleza misma, nos dice, lleva a él y es por ello que «la historia de la humanidad en el aspecto integral puede ser considerada como una realización del designio oculto de la naturaleza». En caso de los individuos la naturaleza se sirve de su egoísmo, pero refiriéndose al género humano como tal ella saca provecho de la guerra como instrumento tan cruel como indispensable. Es justamente en este lugar en que nace el sueño del filósofo sobre la realización de un Estado jurídico y cosmopolita: como la naturaleza misma pre- 
siona hacia la libertad en el reino de los fines, igualmente cada guerra hace presión hacia la realización del ius gentium pacifista. Y es hacia este nuevo mundo que se dirige la faz segunda de Emanuel Kant.

No hay aquí ni tiempo ni lugar para explicar la relación intricada entre los hechos y postulados. Basta decir que en la cuestión del susodicho ius gentium el optimismo de Kant no sabe cómo limitarse. Para desatar el nudo de la historia humana hay que referirse a la esfera del pensamiento postulativo. Lo que resulta de esa estrategia intelectual es el rechazo de toda experiencia histórica. Dirigiéndose al camino trazado por la razón pura, confía Kant en que el ius gentium pudiera contener en última instancia los principios sancionados por la ley positiva y no solamente por las precarias obligaciones, resultados de las costumbres usuales (consensus gentium). Al mismo tiempo, la soberanía de los Estados tendría que desvanecerse a favor del derecho cosmopolita que va a nacer. El derecho cosmopolita kantiano - Weltbürgerrecht - formaría pues una federación de los Estados republicanos, cuyas leyes irían a deshacerse cada vez más en el Derecho internacional. No se puede excluir, nos dice el filósofo, que ese proceso pase las fronteras del mundo viejo para abarcar el mundo entero. Podemos esperar que — como admite Kant — es la misma necesidad la que había forzado a los hombres para que salieran del estado natural y la que va a forzar a los Estados para que renuncien a las guerras como ultima ratio regum. Sin embargo, en ese momento, dice Kant, parece que la naturaleza quiere algo diferente y por eso en vez de la paz perpetua tenemos la tregua y en lugar del Derecho internacional, el equilibrio de fuerzas.

En cuanto a que el Rechtsstaat debería tener su fundamento en un Estado jurídico - llamado por Kant rechtlicher Zustand_-, el dilema de la eficacia del Derecho internacional tendrá que ser solucionado como un problema jurídico y no, como solía ocurrir antes, como un problema moral o habitual. La deducción del Derecho internacional del concepto de Estado natural significaría la creación de le teoría del derecho de guerra. Sin embargo, lo que no debiera ser lícito bajo el Derecho internacional nuevo es el inventar unas justificaciones para la guerra: el fin de la federación nueva de las naciones consistiría más bien en eliminarla completamente de las relaciones internacionales. Ese postulado, como vamos a ver, embarcará a Kant en una red de conclusiones no previstas, siendo ello un resultado necesario de la idea del ius gentium pacifista.

La guerra, como un fenómeno irresistible, ha sida aceptada como tal por todos los pensadores respetables. Aunque Tertuliano, en su obra De corona militis, prohibía a los cristianos tener parte en la guerra, predica- 
ba en el desierto. El pacifismo lo desconocían también los pensadores de la tradición escolástica y neoescolástica, de lo que son un ejemplo claro los tratados de guerra y sus iustae causae de la Escuela de Salamanca. Todos ellos estuvieron de acuerdo acerca de que, aunque no se puede constreñir al dios Marte para que se calle, al menos se puede amansarlo un poco. Pero queda entendido que vim vi repellere licet. Es justamente por eso que son escritos los tratados de guerra como el de Baltasar Ayala, De jure et offcis bellicis et disciplina militari (1582); parece el fin de su obra la interpretación nueva y simplificada del concepto escolástico de la guerra justa. En realidad, Ayala nos quiere persuadir de que en general no se trata más de ella, sino de la guerra formal, la que no pueden hacer los Estados soberanos y legítimos como iusti hostes, es decir, los enemigos formales. La condición sine qua non de esa guerra formal y solemne es su carácter público; esto quiere decir que hay que excluir la guerras privadas, las guerrillas, y dar por enemigos informales a todos sus participantes — piratas, rebeldes, terroristas-. Nos dice Ayala: aliud est hostis, aliud rebellis. Y eso es lo que nos dirá también Tomás Hobbes, pero no Kant.

Supongo que Kant no conoció en profundidad las obras de la escuela española sobre el derecho de la guerra, las obras importantes escritas por Francisco de Vitoria, Luis de Molina, Domingo de Soto, Francisco Suárez o, en último lugar, Baltasar Ayala. Él habría podido conocerlos un poquito por obra de Hugo Grotius. Sea lo que sea, la misma idea de la guerra formalizada por las reglas refiriéndose a declararla, hacerla y llevarla a término - todo eso sin apelar a la imaginación del filósofo, quien había hecho sus proyectos del orden pacifista y jurídico- Podemos suponer que esa visión pacifista y utópica tenía mucho que ver con el pietismo - una variante del protestantismo, en cuya aura él ha sido educado en su infancia en Prusia-. Sea así o no, lo que pasa es que se trata aquí de una confusión de ideas, lo que llevará a Kant a las conclusiones peligrosas acerca del derecho de guerra.

Lo más importante es que Kant niega el estatus jurídico de la guerra afirmando que, por su naturaleza, «existen los Estados en el estado de anarquía» ${ }^{4}$, porque eso es justamente estado de naturaleza (status naturalis). Dicho sea de paso, esa tesis no está conforme con su afirmación de que ya en el estado de naturaleza hubiera algunas formas de propiedad provisional ${ }^{5}$. Sin embargo, él añade que, sin caer en contradicción, no se podría

${ }^{4}$ I. Kant, Die Metaphysik der Sitten, en I. Kant, Werkausgabe, Band VII, Frankfurt am Main, 1982, II, Teil, 54.

5 Ibid., I, Teil, 15. 
hablar del derecho de guerra porque inter arma silent leges. No importa de qué manera sutil serían plasmadas las doctrinas del foedus pacificum o pax romana; aquí se trata de que para la guerra no hay ninguna justificación —ni jurídica, ni moral- Este juicio severo, siendo por cierto el resultado de la observación de las reglas lógicas, lleva a una consecuencia inquietante acerca de la guerra como tal: al no tener nada que ver con la justicia, se queda en calidad de una guerra privada o de una rebeldía y nada más que eso. Esta conclusión no la podría aceptar el Kant con la faz realista. No obstante, en su tratado Zum ewigen Frieden el Kant con la faz pacifista estaba hablando sarcásticamente de los teoréticos del derecho de guerra viejo como «los consoladores deplorables» ${ }^{6}$.

Prescindiendo de la noción clásica de la guerra formal (bellum solenne), toma Kant una posición un poco torpe del moralista pacifista, cuyo resultado será su renuncia a la categoría clásica del enemigo formal (iustus hostis). A pesar de la formulación mencionada de Baltasar Ayala, según la cual aliud est hostis, aliud rebellis ${ }^{7}$, escoge Kant su camino hacia lo que parece un callejón sin salida: la renuncia a esta distinción, indispensable para amansar a dios Marte, no sólo destruye la tradición existente hasta ahora del ius gentium, sino que también implica las consecuencias amenazadoras para el entendimiento contemporáneo de la guerra y del enemigo. En una palabra, lo que pasa es que Kant iba a tergiversar el sentido antiguo de la palabra hostilitas, la que los teoréticos del Derecho internacional de la guerra tomaron usualmente por una categoría jurídica, habiendo tenido miedo de que la guerra se les hubiera podido escapar del control.

Al fin, la utopía pacifista de una federación futura de las naciones iba a verse desbordada por la convicción de que la categoría del enemigo formal (iusti hosti) es justamente la que se desbarata a sí misma por la razón de la contradicción lógica. Eso nos dice Kant:

«El enemigo justo sería aquel a quien yo no podría oponerme sin cometer una injusticia, pues en este caso él no podría ser de ningún modo un enemigo mío» ${ }^{8}$.

La equivocación de Kant parece consistir en la confusión simple de la visión feliz de la justicia como tal con la necesidad prosaica y triste de refrenar

${ }^{6}$ I. Kant, Zum ewigen Frieden, en Kants gesammelte Schriften, Band VIII, Kap. II, Berlin, 1912, p. 357.

7 B. AYALA, De jure et officiis bellicis et disciplina militari, lib. I, cap. II, Madrid, IEP, 1948.

${ }^{8}$ I. Kant, Die Metaphysik der Sitten, op. cit., II, Teil 60. 
la vehemencia de la guerra con ayuda de los procedimientos, respetados por los enemigos formales. En consecuencia, el filósofo echa aceite en el fuego interpretando la expresión iustus hostis como «el enemigo justo», lo que le lleva a las peligrosas connotaciones moralistas, mientras que la palabra latina iustus se puede traducir también como «regular» y es justamente en este sentido como la usaban los teoréticos modernos de la guerra formal. No basta decirlo, porque esta equivocada interpretación moralista llevará después a las consecuencias más peligrosas, a saber, a la introducción de la categoría nueva del enemigo injusto o inicuo (a lo que Kant llama ungerechter Feind): «Su voluntad —nos dice el filósofo— va a mostrar una máxima, la cual —si pudiera hacerse una regla universal— haría imposible el tratado de la paz» . Se puede suponer que en este caso al susodicho iniustus hostis habría que estigmatizarlo como a un enemigo de toda la humanidad. De esta manera, el moralismo pacifista llevaría al concepto de la guerra última y apocalíptica.

Sin sacar conclusiones tan radicales, basta darse cuenta de que por este error doble la filosofía kantiana de la paz perpetua internacional se enredó en las paradojas típicas del concepto pacifista de ius gentium. Así pues, parece que la renuncia a la teoría clásica de la guerra formal, juntamente con la categoría del enemigo formal y la aplicación imprudente de la noción de un enemigo injusto, terminaría con la vuelta indeseable al estado de naturaleza. En fin, hay que notar que el status iuridicus kantiano no supone ningún poder soberano para sancionarlo. No surgiría este estado jurídico de la voluntad del soberano o de la hegemonía internacional, sino simplemente del otro estado jurídico ${ }^{10}$. La falta del soberano o de la hegemonía, la que suponía Kant realista, parece ser un defecto adicional del concepto de ius cosmopoliticum. Es así que en este enfoque el ius cosmopoliticum pierde todo su fundamento efectivo, mientras que la palabra ius habría de ser entendida no en su sentido jurídico — lo que deseaba Kant-, sino moralista y postulativo.

Lo que se puede percibir en la faz doble de Immanuel Kant es la lucha del pesimismo histórico con el racionalismo postulativo. El Kant con la faz del pacifista le mira al Kant realista de las alturas de la razón pura, mientras que el último manda a aquél esperar por un momento histórico conveniente, en el que la humanidad renuncie a la guerra como tal; solamente entonces el Kant realista dejará de ser necesario. Pero hasta que él exista, ambos no podrán tener razón al mismo tiempo.

9 I. KANT, Zum ewigen Frieden, op. cit., Kap. I, p. 343.

${ }^{10}$ Ibid. 